\title{
Sleep and the epidemic of obesity in children and adults
}

\author{
Eve Van Cauter ${ }^{1}$ and Kristen L Knutson ${ }^{2}$ \\ Departments of ${ }^{1}$ Medicine, MC1027 and ${ }^{2}$ Health Studies, University of Chicago, 5841 S. Maryland Avenue Chicago, Illinois 60637, USA \\ (Correspondence should be addressed to E Van Cauter; Email: evcauter@medicine.bsd.uchicago.edu)
}

\begin{abstract}
Sleep is an important modulator of neuroendocrine function and glucose metabolism in children as well as in adults. In recent years, sleep curtailment has become a hallmark of modern society with both children and adults having shorter bedtimes than a few decades ago. This trend for shorter sleep duration has developed over the same time period as the dramatic increase in the prevalence of obesity. There is rapidly accumulating evidence from both laboratory and epidemiological studies to indicate that chronic partial sleep loss may increase the risk of obesity and weight gain. The present article reviews laboratory evidence indicating that sleep curtailment in young adults results in a constellation of metabolic and endocrine alterations, including decreased glucose tolerance, decreased insulin sensitivity, elevated sympathovagal balance, increased evening concentrations of cortisol, increased levels of ghrelin, decreased levels of leptin, and increased hunger and appetite. We also review crosssectional epidemiological studies associating short sleep with increased body mass index and prospective epidemiological studies that have shown an increased risk of weight gain and obesity in children and young adults who are short sleepers. Altogether, the evidence points to a possible role of decreased sleep duration in the current epidemic of obesity.
\end{abstract}

European Journal of Endocrinology 159 S59-S66

\section{The epidemic of obesity and sleep curtailment in adults and in children}

The prevalence of obesity is increasing worldwide, particularly in the US (1). In 2004, more than onethird of American adults were overweight or obese (2). Rates of overweight and obesity have also increased in all industrialized countries, although prevalence is still lower than that in the US. Figure 1 shows the prevalence of obesity (body mass index (BMI) $>30 \mathrm{~kg} / \mathrm{m}^{2}$ ) in selected European countries in 1998 and 2001 (3). Prevalence rates range from less than $8 \%$ to nearly $14 \%$, depending on country and sex, and remarkably the proportion of obese individuals in the general adult population increased over the 3-year follow-up period in all but one country. The epidemic of obesity has not spared children. Figure 2 shows the increase in prevalence of overweight among the US children of ages $2-5,6-11$, and $12-19$ years from the early seventies to 2003-2004 (4). In each age group, the prevalence of overweight approximately tripled over these three decades.

The causes of this epidemic are not fully explained by the changes in traditional lifestyle factors such as diet

This paper was presented at the 5th Ferring International Paediatric Endocrinology Symposium, Baveno, Italy (2008). Ferring Pharmaceuticals has supported the publication of these proceedings. (increases in food intake, food portions, and snacking) and decreases in physical activity. It has been recently proposed that shorter habitual sleep times may also be on the causal pathways $(5,6)$. Indeed, one behavior that seems to have developed over the past few decades and has become highly prevalent, particularly among Americans, is sleep curtailment. In 1960, a survey study conducted by the American Cancer Society found modal sleep duration to be 8.0 to $8.9 \mathrm{~h}$ (7), while in 1995 the modal category of the survey conducted by the National Sleep Foundation poll had dropped to $7 \mathrm{~h}$ (8). Today, more than $30 \%$ of adult men and women between the ages of 30 and 64 years report sleeping less than $6 \mathrm{~h}$ per night (9).

Very few studies have assessed usual sleep duration using objective measures, rather than self-report. One of the first attempts was a population-based study of 273 volunteers aged 40-60 years in San Diego, California. This study measured sleep by wrist actigraphy in 19901994 and found mean sleep duration to be $6.2 \mathrm{~h}$ (10). The Sleep Heart Health Study used a single night of in-home polysomnography among 2685 participants with a mean age of 62 years, and the average sleep time was $6.1 \mathrm{~h}$ for women and $5.7 \mathrm{~h}$ for men (11). More recently, an ancillary study to the Coronary Artery Risk Development in Young Adults (CARDIA) study, a prospective multi-center cohort study of the evolution of cardiovascular risk factors begun in 1985, measured sleep in participants aged 38-50 years using wrist 

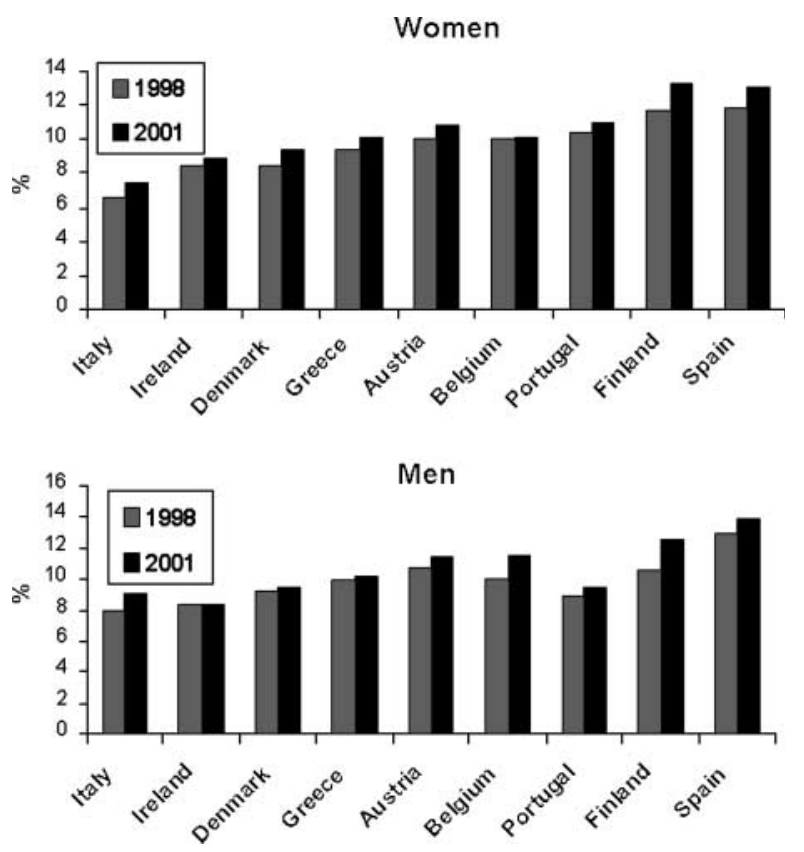

Figure 1 Prevalence of obesity $\left(\mathrm{BMl}>30 \mathrm{~kg} / \mathrm{m}^{2}\right)$ in nine European countries in 1998 and 2001 (adapted from Ref. (3)).

actigraphy for three consecutive days in 2003-2004 (12). In the CARDIA sleep study, mean $( \pm$ s.D.) for sleep duration was $6.1(1.2) \mathrm{h}$, and varied between the racesex groups from $6.7(0.9) \mathrm{h}$ in white women to $5.1(1.3)$ $\mathrm{h}$ in African-American men (12). Insufficient sleep appears also highly prevalent in the US children. Thus, all three studies that assessed sleep duration objectively in the US adults found very similar means of sleep duration.

Laboratory studies have shown that 'sleep need,' defined as the amount of sleep achieved when given $10 \mathrm{~h}$ of nocturnal bedtime, does not change substantially across adolescence (10-17 years) and is about $9 \mathrm{~h}$ (13). Contrasting with this physiological sleep need of $9 \mathrm{~h}$ are self-reported sleep durations collected in a sample representative of the US in a 2006 survey conducted by the US National Sleep Foundation (14). As shown in Fig. 3, mean sleep duration was under $9 \mathrm{~h}$ in

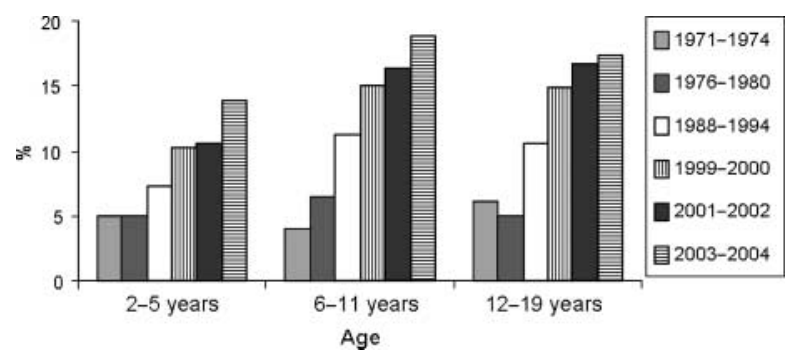

Figure 2 Prevalence of overweight (defined as above the 95th percentile for age and sex) among the US children of ages $2-5$, 6-11, and 12-19 years in 1971-1972, 1976-1980, 1988-1994, 1999-2000, 2001-2002, and 2003-2004 (adapted from Ref. (4)).

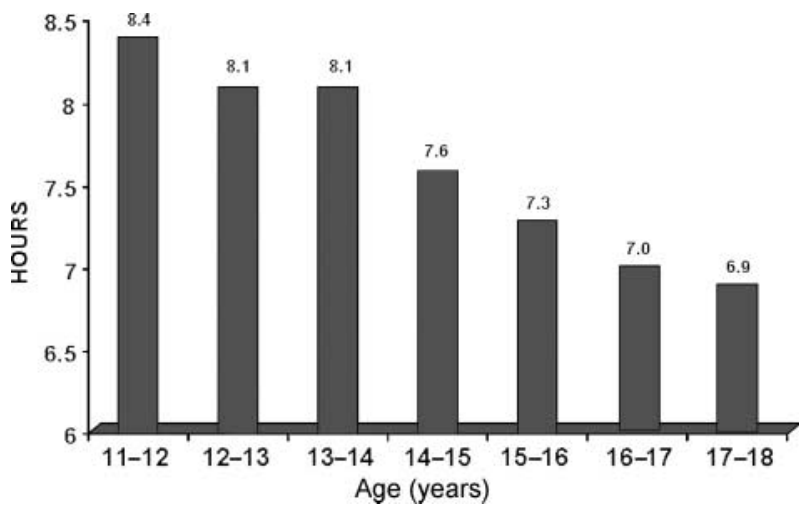

Figure 3 Self-reported sleep duration (hours) by age for the US children aged $11-18$ years (14).

all age groups and decreased steadily from $8.4 \mathrm{~h}$ at ages 11-12 years to only $6.9 \mathrm{~h}$ at ages $17-18$ years. Furthermore the study showed that the decrease in sleep duration was mostly due to later bedtimes, rather than earlier wake up times, and that the respondents were aware of having insufficient sleep.

The decrease in average sleep duration in the US has occurred over the past three to four decades, simultaneous with the increase in the prevalence of obesity. In recent years, data from both laboratory and epidemiological studies have accumulated to support the hypothesis that sleep curtailment may have contributed to the increased prevalence of overweight and obesity. Sleep curtailment may affect energy balance and result in weight gain via three distinct pathways: upregulation of appetite, more time to eat, and/or a decrease in energy expenditure. Significant weight gain may in turn result in insulin resistance, a condition that may promote further adiposity. Additionally, up to $20 \%$ of overweight and obese individuals suffer from sleep-disordered breathing (SDB), an independent risk factor for insulin resistance $(15,16)$. Indeed, there is a substantial body of evidence to indicate that sleep fragmentation, hypoxia, and low levels of deep non-rapid eye movement (REM) sleep as occur in SDB may all contribute to reduce insulin sensitivity (16-18). The present article will, however, focus on sleep loss resulting only from behavioral sleep restriction rather than that from the presence of a sleep disorder.

\section{Laboratory studies linking sleep loss and upregulation of appetite}

Early studies reported increased food intake in human subjects and in laboratory rodents submitted to total sleep deprivation $(19,20)$. More recent studies that have examined appetite regulation under the much more common condition of partial chronic sleep deprivation are summarized below. 


\section{The 'Sleep Debt Study': 6 days with 4-h bedtimes}

The first detailed laboratory study that examined the effects of recurrent partial sleep deprivation on hormonal and metabolic variables involved in appetite regulation included healthy young men who were subjected to six nights of $4 \mathrm{~h}$ in bed ('sleep debt') followed by seven nights of $12 \mathrm{~h}$ in bed ('sleep recovery') (21). The subjects also underwent a baseline study with the recommended 8-h bedtimes. They ate identical carbohydrate-rich meals and were at continuous bed rest on the last 2 days of each bedtime condition. At the end of each condition, the subjects underwent an i.v. glucose tolerance test (ivGTT) followed by a 24-h period of blood sampling at 10-30 min intervals to assess glucose and hormonal profiles.

The upper panels of Fig. 4 shows the mean profiles of plasma leptin observed under the three conditions (22). Leptin is a peripheral endocrine signal released by the adipocytes, which conveys information regarding energy balance to the brain. Leptin is a satiety factor: high leptin levels inhibit and low leptin levels stimulate hunger and food intake respectively. The data shown in Fig. 4 demonstrate that leptin levels are remarkably sensitive to sleep duration, with a 'dose-response' relationship between sleep duration and leptin consistent with increased hunger when sleep is curtailed. Indeed, on average, mean leptin levels were 19\% lower when the subjects had $4 \mathrm{~h}$ in bed than when they were presumably fully rested, after 6 days with $12 \mathrm{~h}$ in bed.
The normal nocturnal acrophase of peripheral leptin concentrations was $2 \mathrm{~h}$ earlier and 26\% lower and the amplitude of the diurnal variation was $20 \%$ lower during sleep restriction when compared with the fully rested condition (22). Remarkably, these changes occurred despite identical caloric intake. Differences in energy expenditure between the two bedtime conditions were minimal because the subjects were at bed rest. In ongoing studies, our group has preliminary evidence indicating that the extension of the waking period in humans studied under comfortable sedentary conditions is not associated with an increase in energy requirement as assessed by the doubly labeled water method (23). The difference in maximal leptin levels between the state of sleep debt and the fully rested state was somewhat larger than the decrease reported in a separate study in young adults submitted to 3 days of dietary intake restricted to $70 \%$ of energy requirements (a caloric deficit of $\sim 900 \mathrm{kcal} /$ day) (24). Thus, in the state of sleep debt, leptin levels were inaccurately signaling a state of substantial caloric deficit. Unfortunately, subjective feelings of hunger and appetite were not assessed in this first 'Sleep Debt Study'.

It is well known that glucocorticoids increase food intake and, in the same Sleep Debt Study, alterations in the 24-h profile of circulating cortisol levels were also observed (shown in the middle panels of Fig. 4). While 24-h mean levels were similar under the three bedtime conditions, sleep duration affected cortisol levels in the late afternoon and evening (shaded areas) with a graded

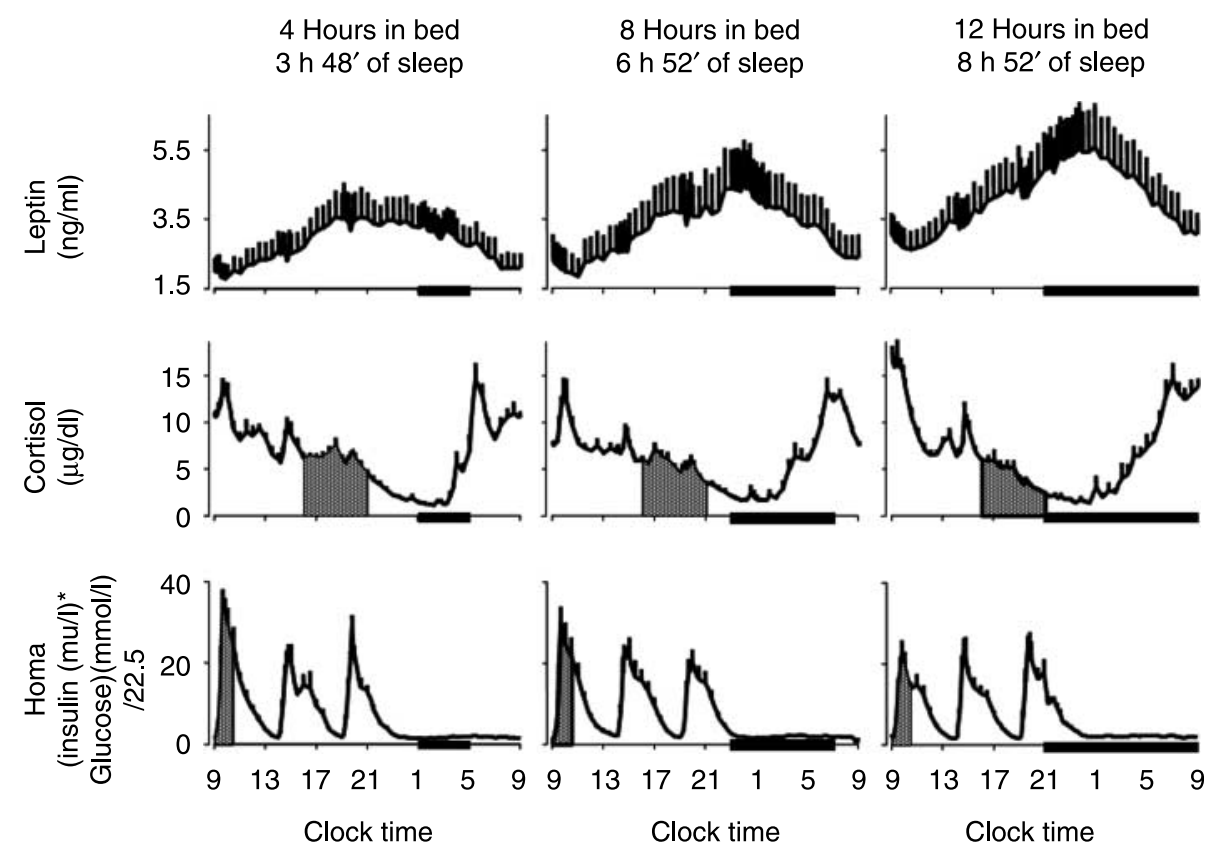

Figure 4 Mean ( \pm s.E.M.) 24-h leptin, cortisol, and HOMA profiles with 4-, 8-, and 12-h bedtimes. Note that the relative synchronization of the leptin and cortisol profiles in the study with 8-h bedtimes was intermediate between that observed with 4-h bedtimes and that observed with 12-h bedtimes. Similarly, the HOMA response to breakfast gradually increased from the 12-h bedtime condition to the 4-h bedtime condition, with an intermediate response during the 8-h bedtime condition. Black bars, Sleep periods. (Copied with permission from Ref. (22)). 
inverse relationship between sleep duration and cortisol levels (22). The nadir of cortisol concentrations occurred $\sim 1.5 \mathrm{~h}$ later when subjects had 4 -h bedtimes as compared with when they had 12-h bedtimes. Leptin and cortisol levels varied in a mirror image throughout the 24-h cycle when the subjects were fully rested, and maximum leptin levels were essentially aligned with minimum cortisol concentrations. This inverse relationship was disrupted following sleep restriction. Leptin levels stopped rising in the early evening, when cortisol concentrations were still declining, and this curtailment of the leptin elevation was quantitatively associated with the concomitant elevation of evening cortisol levels. The study further revealed that alterations of the 24-h leptin profile resulting from sleep restriction in healthy individuals studied under conditions of stable caloric intake and activity levels were associated with an increase in cardiac sympathovagal balance (22).

Another finding of this first laboratory study of metabolic alterations resulting from the experimental buildup of a sleep debt was a nearly $40 \%$ decrease in glucose tolerance to levels consistent with a state of impaired glucose tolerance (21). Reduced glucose tolerance to ivGTT was associated with a marked reduction in acute insulin response to glucose and a trend for reduced insulin sensitivity. The combination of these two defects resulted in a marked decrease in the so-called disposition index (DI), a validated marker of diabetes risk where low DI values indicate an elevated risk of type 2 diabetes. The lower panels of Fig. 4 show the profiles of homeostasis model assessment (HOMA) values (glucose concentration $(\mathrm{mmol} / \mathrm{l}) \times$ insulin concentration (mIU/l) divided by 22.5$)$ calculated for each time point. Fasting levels of HOMA are a validated measure of insulin sensitivity, but HOMA values during meal ingestion were used here as an integrated measure of the glucose and insulin responses to the three identical carbohydrate-rich meals ingested during the study. The post-breakfast HOMA (shown as a shaded area) was significantly elevated $(+56 \%)$ when the subjects were in a state of sleep debt, as compared with fully rested, and the response was intermediate when the subjects had $8 \mathrm{~h}$ in bed. Subsequent studies of more extended periods of less rigorous sleep restriction (e.g. 8 nights with $5 \mathrm{~h}$ in bed) have revealed a consistent decline in insulin sensitivity without appropriate compensation by $\beta$-cell responsiveness, and thus an increase in diabetes risk. In summary, reduced insulin sensitivity is another possible mechanism by which a state of sleep debt might increase the risk of weight gain and obesity.

\section{Randomized crossover design study: 2 days of $4 \mathrm{vs} 10 \mathrm{~h}$ in bed}

The initial Sleep Debt Study involved a possible order effect since sleep recovery during extended nights follows the buildup of the sleep debt. A subsequent laboratory study addressed this limitation by using a randomized crossover design to compare the impact of restricted versus extended sleep and observed consistent effects of sleep restriction on appetite regulation (25). This study involved 2 days of 4-h bedtimes and 2 days of 10-h bedtimes in subjects receiving a constant glucose infusion as their only source of caloric intake. Daytime levels of leptin, ghrelin, hunger, and appetite were measured at frequent intervals after the second night of sleep restriction or extension (25). Ghrelin is a hunger hormone primarily secreted by the stomach, which appears to act independently of leptin. Table 1 summarizes the changes in leptin, ghrelin, hunger, and appetite when sleep was restricted as compared to extended (25). Importantly, the change in the ratio of ghrelin-to-leptin between the two conditions was strongly correlated to the change in hunger ratings, suggesting that the changes observed in these appetite hormones were partially responsible for the increase in appetite and hunger. These observed changes would suggest that these subjects, if allowed unlimited amounts of food, would have increased their food intake. After sleep restriction, the increase in appetite was particularly strong for nutrients with a high carbohydrate content (Table 1) as if the sleepdeprived brain craved its primary fuel, glucose.

\section{Population-based studies}

Two population-based studies in adults, The Wisconsin Sleep Cohort Study (26) and the 'Quebec en Forme' study from Canada (27) also observed an association between short sleep duration and changes in leptin and/or ghrelin consistent with an upregulation of appetite. Both studies included a large number of subjects, measured hormonal levels on a single sample, and controlled for the degree of adiposity. Remarkably, as illustrated in Fig. 5, the findings from these two

Table 1 Summary of effects of 4- and 10-h bedtimes hunger and appetite were measured on visual analogue scales.

\begin{tabular}{|c|c|c|c|c|}
\hline Mean $( \pm$ S.E.M. $)$ levels & $\begin{array}{l}\text { After } 2 \text { days of } 4-h \\
\text { bedtime }\end{array}$ & $\begin{array}{l}\text { After } 2 \text { days of } 10-h \\
\text { bedtime }\end{array}$ & Change (\%) & $\boldsymbol{P}$ \\
\hline Plasma leptin (ng/ml) & $2.1 \pm 0.4$ & $2.6 \pm 0.5$ & -18 & 0.04 \\
\hline Plasma ghrelin (ng/ml) & $3.3 \pm 0.2$ & $2.6 \pm 0.2$ & +28 & $<0.04$ \\
\hline Ghrelin/leptin ratio & $2.3 \pm 0.4$ & $1.6 \pm 0.3$ & +71 & $<0.07$ \\
\hline Hunger $(0-10 \mathrm{~cm})$ & $7.2 \pm 0.4$ & $6.0 \pm 0.5$ & +24 & $<0.01$ \\
\hline Global appetite $(0-70 \mathrm{~cm})$ & $47.7 \pm 3.4$ & $39.7 \pm 3.0$ & +23 & 0.01 \\
\hline Appetite for high carbohydrate food $(0-30 \mathrm{~cm})$ & $20.6 \pm 1.4$ & $16.3 \pm 1.3$ & +32 & $<0.02$ \\
\hline Appetite for other food types $(0-40 \mathrm{~cm})$ & $27.1 \pm 2.2$ & $23.4 \pm 1.8$ & +18 & $<0.2$ \\
\hline
\end{tabular}



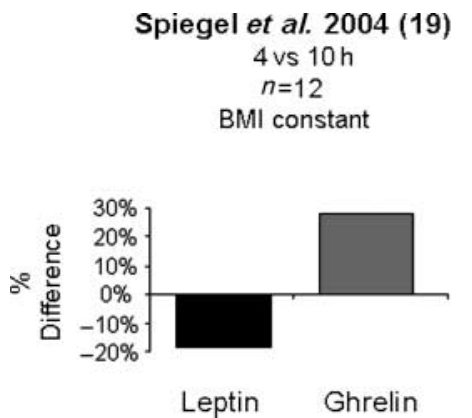

Taheri et al. $2004(20)$

5 vs $8 \mathrm{~h}$

$n=1024$

BMI adjustment

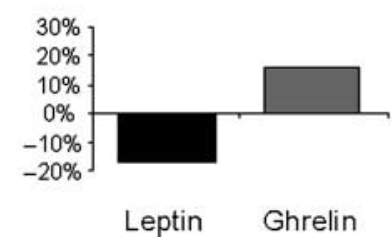

Chaput et al. 2007 (21)

$5-6 \mathrm{~h}$ vs level predicted

by BMI

$n=740$

Body fat adjustment

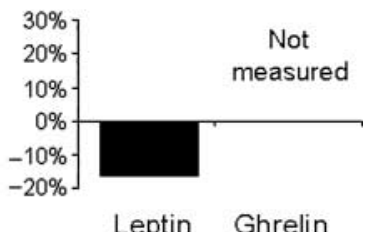

Figure 5 Percent difference in levels of leptin and ghrelin comparing short sleep to longer sleep conditions from three different studies (25-27).

population studies were qualitatively and quantitatively in agreement with the findings of the laboratory study.

A recent report examining sleep duration, resting energy expenditure, and leptin levels in children and adolescents aged 6-20 years found that resting energy expenditure was lower among short sleepers in boys after an adjustment for age and fat free mass, and that leptin levels were higher among short sleepers in girls after an adjustment for waist circumference (28). These results suggest a possible gender difference in the impact of sleep duration on leptin levels and energy expenditure, at least during childhood and adolescence.

\section{Epidemiological studies linking short sleep and increased risk of obesity}

A rapidly growing body of epidemiological evidence supports the findings from the laboratory studies. Table 2 summarizes the studies published as of April 10, 2008. Taken together, the studies have involved thousands of subjects, both adults and children of all ages. They have originated from multiple industrialized countries and have involved diverse populations in terms of sex, age, and BMI distribution. Patel \& Hu (29) have recently provided a careful review of the evidence and pointed out that the impact of short sleep on obesity risk appears greater in children than adults, and greater in young adulthood than in midlife or late life. This systematic review identified six cross-sectional studies with negative findings or with positive findings in only one sex group (out of a total of 20 cross-sectional studies in adults included in this analysis). One of the studies characterized as negative (12) focused on race-sex differences in sleep duration and quality objectively assessed by wrist actigraphy in the CARDIA Chicago cohort. Indeed, in this analysis, BMI was not a significant mediator of race-sex differences in sleep. For the purpose of the present article, we identified five more cross-sectional studies in adults not included in the Patel \& Hu review (30-34) and therefore, to date, there have only been four studies $(32,35-37)$ out of a total of 25 that have not observed a cross-sectional association between short sleep and the risk of overweight/obesity in adults of either sex. Of note, two of these studies included only participants over 50 years of age $(32,35)$. Cross-sectional studies cannot address the causal direction between sleep duration and weight; however, there have also been prospective studies that have observed an association between sleep duration and weight gain, including four studies in children (38-41) and five in adults $(30,42-45)$. All but one (30) of these prospective studies found a significant association between shorter sleep duration at baseline and greater weight gain during the period of follow-up.

Table 2 Number of published epidemiological studies on the relationship between sleep duration and body mass index (BMI) or prevalence or incidence of overweight/obesity.

\begin{tabular}{|c|c|c|c|c|c|c|}
\hline & \multicolumn{2}{|c|}{ Number of studies in children } & \multicolumn{2}{|c|}{ Number of studies in adults } & \multicolumn{2}{|c|}{ Total number of studies } \\
\hline & Positive findings & $\begin{array}{l}\text { Total number of } \\
\text { studies }\end{array}$ & Positive findings & $\begin{array}{l}\text { Total number of } \\
\text { studies }\end{array}$ & Positive findings & $\begin{array}{c}\text { Total number of } \\
\text { studies }\end{array}$ \\
\hline $\begin{array}{l}\text { Cross-sectional } \\
\text { studies }\end{array}$ & 13 & 13 & 21 & 25 & 34 & 38 \\
\hline $\begin{array}{l}\text { Prospective } \\
\text { studies }\end{array}$ & 4 & 4 & 4 & 5 & 8 & 9 \\
\hline All studies & 7 & 7 & 25 & 30 & 42 & 47 \\
\hline
\end{tabular}

References for each study can be found in the 2008 review by Patel \& Hu (30) with the following additions that were not included in the Patel \& Hu review. Cross-sectional studies in children: Nixon, Sleep 2008 (55) and Yu, Sleep 2007 (56). Cross-sectional studies in adults: Stranges, AJE 2008 (30); Lopez-Garcia AJCN 2008 (31), Littman et al. 2006 (negative) (32), Rontoyanni 2007 (33), Bjorvatn 2007 (34). Prospective studies in children: Lumeng et al. (40), Taveras et al. 2008 (41), prospective studies in adults: Chaput et al. 2008 (45), Stranges, AJE 2008 (30). 


\section{Putative mechanisms linking sleep loss and risk of weight gain and obesity}

In summary, the findings from laboratory studies indicate that reduced sleep duration may increase the risk of weight gain and obesity by upregulating appetite via a decrease in leptin, an increase in ghrelin, and a reduction in insulin sensitivity. Limited evidence from population studies support a role for leptin in the link between short sleep and higher BMI.

It is likely that the orexin system is pivotal in these interactions between sleeping and feeding. Orexins (also called hypocretins) are two distinct peptides (orexin A and B) that were discovered in 1998 and are synthesized mainly by neurons in the lateral hypothalamus. These neurons play a central role in the maintenance of arousal. Orexins (as suggested by their name) also increase feeding $(46,47)$, particularly at a time when normal food intake is low. Feeding requires the maintenance of wakefulness and the orexin system appears to be the crucial link in this vital interaction between feeding and arousal. Orexin neurons are active during the waking phase, in synchrony with neuronal activity in other arousal centers, and inactive during slow-wave sleep. Orexins activate all the components of the ascending arousal system, and orexin neurons also project diffusely to the entire cerebral cortex (48). Consistent with the fact that sympathetic nervous activity is higher during waking than during sleeping, orexin activity is associated with increased sympathetic tone, and excitatory effects of the orexin peptides have been observed for neurons of the nucleus tractus solitarius and for neurons of the hypothalamic paraventricular nucleus (49). In animal models, sleep deprivation upregulates central orexin activity (5052). Higher orexinergic activity promotes sympathetic nervous tone and activity of the appetite-stimulating neuropeptide Y (NPY) neurons of the arcuate nucleus.

Increased sympathetic nervous activity associated with sleep deprivation is a likely mediator of several of the peripheral effects of sleep loss, including the reduction in leptin release from the adipocytes, the reduction in total body insulin sensitivity, and the failure of $\beta$-cells to adequately compensate for the decrease in insulin sensitivity.

The notion of 'leptin resistance' has been introduced to explain the paradoxical observation that most obese individuals have high, rather, than low plasma leptin levels, despite their ample energy stores. While a number of putative mechanisms have been proposed to underlie leptin resistance, one suggestion that may be particularly relevant to the studies of sleep loss is the hypothesis that leptin binds to circulating levels of C-reactive protein (CRP), an inflammatory marker that is elevated in obesity (53). Higher CRP levels would result in a decrease in unbound, free leptin with a reduction in its central actions. Several studies of acute total sleep deprivation as well as recurrent partial sleep deprivation in healthy lean adults have reported an elevation of CRP with sleep loss (54) and ongoing studies from our laboratory confirm these findings. The combination of reduced leptin levels with increased CRP concentrations in sleep-deprived subjects may amplify the effects of the leptin reduction alone.

\section{Conclusions}

Findings from laboratory studies in young adults and epidemiological studies in both children and adults converge to suggest that partial chronic sleep restriction, an increasingly prevalent behavior in modern society, may increase the risk of weight gain and play a role in the current epidemic of obesity.

One of the many present challenges for this emerging field of enquiry will be to translate the findings from short-term well-controlled laboratory studies in small numbers of subjects to the lifetime trajectory of weight gain observed in large populations. Thus, laboratory studies will need to be complemented by the studies conducted in real-life conditions over longer periods of follow-up with an accurate monitoring of sleep duration and quality and energy balance. Another important issue is the temporal window of metabolic vulnerability to sleep loss. Indeed, whether sleep restriction may have a different impact in normal weight individuals with high insulin sensitivity, i.e. prior to the development of obesity, versus obese individuals with low insulin sensitivity, i.e. when obesity is already established, is not known. When comparing epidemiological studies originating from different countries (e.g. Europe versus US), it should be noted that the negative relationship between sleep duration and BMI has been found for populations with variable degrees of obesity. The observation that the impact of sleep duration and quality on the risk of obesity may be greater in children than adults suggests that efforts to educate the public regarding the potential deleterious effects of sleep curtailment on long-term health and well-being should start in early life and involve parents, educators, and health care providers.

\section{Funding}

Some of the research described in this article was supported by the US National Institute of Health grants PO1 AG-11412, RO1 HL-075079, P60 DK-20595, R01 DK0716960, and M01 RR000055 and by the US Department of Defense award W81XWH-07-2-0071.

\section{Disclosure}

This paper forms part of a European Journal of Endocrinology supplement, supported by Ferring Pharmaceuticals. The authors disclose: Dr Van Cauter received an honorarium from Ferring for preparing and presenting this work, Dr Knutson has no involvement with Ferring. This article was subject to rigorous peer review before acceptance and publication. 


\section{References}

1 Mokdad A, Bowman B, Ford E, Vinicor F, Marks J \& Koplan J. The continuing epidemics of obesity and diabetes in the United States. Journal of the American Medical Association 2001286 1195-1200.

2 Ogden CL, Carroll MD, Curtin LR, Mcdowell MA, Tabak CJ \& Flegal KM. Prevalence of overweight and obesity in the United States, 1999-2004. Journal of the American Medical Association 2006295 1549-1555.

3 Sanz De Galdeano A The Obesity Epidemic in Europe The Obesity Epidemic in Europe Centre for Studies in Economics and Finance, University of Salerno.

4 Centers for Disease Control and Prevention. Prevalence of Overweight Among Children and Adolescents: United States, 2003-2004 [online]. Available from: http://www.cdc.gov/nchs/products/pubs/ pubd/hestats/overweight/overwght_child_03.htm. Last accessed: April 12, 2008.

5 Locard E, Mamelle N, Billette A, Miginiac M, Munoz F \& Rey S. Risk factors of obesity in a five year old population. Parental versus environmental factors. International Journal of Obesity and Related Metabolic Disorders $199216721-729$.

6 Keith SW, Redden DT, Katzmarzyk PT, Boggiano MM, Hanlon EC, Benca RM, Ruden D, Pietrobelli A, Barger JL, Fontaine KR, Wang C, Aronne LJ, Wright SM, Baskin M, Dhurandhar NV, Lijoi MC, Grilo CM, Deluca M, Westfall AO \& Allison DB. Putative contributors to the secular increase in obesity: exploring the roads less traveled. International Journal of Obesity 200630 1585-1594.

7 Kripke D, Simons R, Garfinkel L \& Hammond E. Short and long sleep and sleeping pills. Is increased mortality associated? Archives of General Psychiatry 197936 103-116.

8 Gallup Organization. Sleep in America Princeton, NJ: Gallup Organization, 1995.

9 National Center for Health Statistics. QuickStats: percentage of adults who reported an average of $\leq 6$ hours of sleep per 24-hour period, by sex and age group - United States, 1985 and 2004. Morbidity and Mortality Weekly Report 200554933.

10 Jean-Louis G, Kripke DF, Ancoli-Israel S, Klauber MR \& Sepulveda RS. Sleep duration, illumination, and activity patterns in a population sample: effects of gender and ethnicity. Biological Psychiatry 200047 921-927.

11 Redline S, Kirchner HL, Quan SF, Gottlieb DJ, Kapur V \& Newman A. The effects of age, sex, ethnicity, and sleep-disordered breathing on sleep architecture. Archives of Internal Medicine 2004 164 406-418.

12 Lauderdale D, Knutson K, Yan L, Rathouz P, Hulley SB, Sidney S \& Liu K. Objectively measured sleep characteristics among early middle-aged adults: the CARDIA Study. American Journal of Epidemiology $2006 \mathbf{1 6 4} 5-16$.

13 Carskadon MA \& Acebo C. Regulation of sleepiness in adolescents: update, insights, and speculation. Sleep 200225 606-614.

14 National Sleep Foundation. Sleep in America Poll Washington, DC: National Sleep Foundation, 2006.

15 Spiegel K, Knutson K, Leproult R, Tasali E \& Van Cauter E. Sleep loss: a novel risk factor for insulin resistance and Type 2 diabetes. Journal of Applied Physiology 200599 2008-2019.

16 Tasali E, Mokhlesi B \& Van Cauter E. Obstructive sleep apnea and type 2 diabetes: interacting epidemics. Chest 2008133 496-506.

17 Punjabi NM, Shahar E, Redline S, Gottlieb DJ, Givelber R \& Resnick HE. Sleep-disordered breathing, glucose intolerance, and insulin resistance: the Sleep Heart Health Study. American Journal of Epidemiology $2004160521-530$.

18 Tasali E, Leproult R, Ehrmann DA \& Van Cauter E. Slow-wave sleep and the risk of type 2 diabetes in humans. PNAS 2008105 1044-1049.

19 Rechtschaffen A \& Bergmann BM. Sleep deprivation in the rat by the disk-over-water method. Behavioural Brain Research 199569 55-63.

20 Dinges D \& Chugh D. Physiological correlates of sleep deprivation. In Physiology, Stress, and Malnutrition: Functional Correlates, Nutritional Intervention, p 668. Eds J Kinney \& H Tucker, Philadelphia, PA: Lippincott Williams \& Wilkins, 1997.
21 Spiegel K, Leproult R \& Van Cauter E. Impact of sleep debt on metabolic and endocrine function. Lancet 1999354 1435-1439.

22 Spiegel K, Leproult R, L'hermite-Baleriaux M, Copinschi G, Penev P \& Van Cauter E. Leptin levels are dependent on sleep duration: relationships with sympathovagal balance, carbohydrate regulation, cortisol, and thyrotropin. Journal of Clinical Endocrinology and Metabolism 200489 5762-5771.

23 Nedeltcheva A, Kilkus J, Imperial JG, Kasza K, Schoeller D \& Penev P. Sleep restriction results in increased consumption of energy from snacks. Sleep 200831 A118-A119.

24 Chin-Chance C, Polonsky KS \& Schoeller D. Twenty-four hour leptin levels respond to cumulative short-term energy imbalance and predict subsequent intake. Journal of Clinical Endocrinology and Metabolism 200085 2685-2691.

25 Spiegel K, Tasali E, Penev P \& Van Cauter E. Sleep curtailment in healthy young men is associated with decreased leptin levels, elevated ghrelin levels and increased hunger and appetite. Annals of Internal Medicine $2004141846-850$.

26 Taheri S, Lin L, Austin D, Young T \& Mignot E. Short sleep duration is associated with reduced leptin, elevated ghrelin, and increased body mass index (BMI). Sleep 200427 A146-A147.

27 Chaput JP, Despres JP, Bouchard C \& Tremblay A. Short sleep duration is associated with reduced leptin levels and increased adiposity: results from the Quebec family study. Obesity 200715 253-261.

28 Hitze B, Bosy-Westphal A, Bielfeldt F, Settler U, Plachta-Danielzik S, Pfeuffer M, Schrezenmeir J, Monig H \& Muller MJ. Determinants and impact of sleep duration in children and adolescents: data of the Kiel Obesity Prevention Study. European Journal of Clinical Nutrition, 2008 (in press)/doi:10.1038/ejcn.2008.41.

29 Patel SR \& Hu FB. Short sleep duration and weight gain: a systematic review. Obesity 200816 643-653.

30 Stranges S, Cappuccio FP, Kandala NB, Miller MA, Taggart FM, Kumari M, Ferrie JE, Shipley MJ, Brunner EJ \& Marmot MG. Crosssectional versus prospective associations of sleep duration with changes in relative weight and body fat distribution: the Whitehall II Study. American Journal of Epidemiology 2008167 321-329.

31 Lopez-Garcia E, Faubel R, Leon-Munoz L, Zuluaga MC, Banegas JR \& Rodriguez-Artalejo F. Sleep duration, general and abdominal obesity, and weight change among the older adult population of Spain. American Journal of Clinical Nutrition 200887 310-316.

32 Littman AJ, Vitiello MV, Foster-Schubert K, Ulrich CM, Tworoger SS, Potter JD, Weigle DS \& Mctiernan A. Sleep, ghrelin, leptin and changes in body weight during a 1-year moderateintensity physical activity intervention. International Journal of Obesity 200631 466-475.

33 Rontoyanni VG, Baic S \& Cooper AR. Association between nocturnal sleep duration, body fatness, and dietary intake in Greek women. Nutrition 200723 773-777.

34 Bjorvatn B, Sagen IM, Oyane N, Waage S, Fetveit A, Pallesen S \& Ursin R. The association between sleep duration, body mass index and metabolic measures in the Hordaland Health Study. Journal of Sleep Research 200716 66-76.

35 Ohayon MM. Interactions between sleep normative data and sociocultural characteristics in the elderly. Journal of Psychosomatic Research 200456 479-486.

36 Amagai Y, Ishikawa S, Gotoh T, Doi Y, Kayaba K, Nakamura Y \& Kajii E. Sleep duration and mortality in Japan: the Jichi Medical School Cohort Study. Journal of Epidemiology 200414 124-128.

37 Gortmaker SL, Dietz WH Jr \& Cheung LW. Inactivity, diet, and the fattening of America. Journal of the American Dietetic Association 199090 1247-1252 (1255).

38 Agras WS, Hammer LD, Mcnicholas F \& Kraemer HC. Risk factors for childhood overweight: a prospective study from birth to 9.5 years. Journal of Pediatrics 2004145 20-25.

39 Reilly J, Armstrong J, Dorosty A, Emmett P, Ness A, Rogers I, Steer C \& Sherriff A. Early life risk factors for obesity in childhood: cohort study. BMJ 20053301357.

40 Lumeng JC, Somashekar D, Appugliese D, Kaciroti N, Corwyn RF \& Bradley RH. Shorter sleep duration is associated with increased risk for being overweight at ages 9 to 12 years. Pediatrics 2007 120 1020-1029. 
41 Taveras EM, Rifas-Shiman SL, Oken E, Gunderson EP \& Gillman MW. Short sleep duration in infancy and risk of childhood overweight. Archives of Pediatrics and Adolescent Medicine 2008162 305-311.

42 Patel SR, Malhotra A, White DP, Gottlieb DJ \& Hu FB. Association between reduced sleep and weight gain in women. American Journal of Epidemiology $2006164947-954$.

43 Gangwisch JE, Malaspina D, Boden-Albala B \& Heymsfield SB. Inadequate sleep as a risk factor for obesity: analyses of the NHANES I. Sleep 200528 1289-1296.

44 Hasler G, Buysse D, Klaghofer R, Gamma A, Ajdacic V, Eich D, Rössler W \& Angst J. The association between short sleep duration and obesity in young adults: a 13-year prospective study. Sleep 200427 661-666.

45 Chaput JP, Despres JP, Bouchard C \& Tremblay A. The association between sleep duration and weight gain in adults: a 6 -year prospective study from the Quebec Family Study. Sleep 200831 517-523.

46 Sakurai T. Roles of orexin/hypocretin in regulation of sleep/wakefulness and energy homeostasis. Sleep Medicine Reviews 20059 231-241.

47 De Lecea L \& Sutcliffe JG. The hypocretins and sleep. FEBS Journal $20052725675-5688$.

48 Saper CB, Chou TC \& Elmquist JK. The need to feed: homeostatic and hedonic control of eating. Neuron 200236 199-211.

49 Samson WK, Taylor MM \& Ferguson AV. Non-sleep effects of hypocretin/orexin. Sleep Medicine Reviews 20059 243-252.

$50 \mathrm{Wu}$ MF, John J, Maidment N, Lam HA \& Siegel JM. Hypocretin release in normal and narcoleptic dogs after food and sleep deprivation, eating, and movement. American Journal of Physiology. Regulatory, Integrative and Comparative Physiology $2002 \mathbf{2 8 3}$ R1079-R1086.
51 Estabrooke IV, Mccarthy MT, Ko E, Chou TC, Chemelli RM, Yanagisawa M, Saper CB \& Scammell TE. Fos expression in orexin neurons varies with behavioral state. Journal of Neuroscience 2001 21 1656-1662.

52 Zeitzer JM, Buckmaster CL, Lyons DM \& Mignot E. Increasing length of wakefulness and modulation of hypocretin-1 in the wake-consolidated squirrel monkey. American Journal of Physiology. Regulatory, Integrative and Comparative Physiology 2007293 R1736-R1742.

53 Chen K, Li F, Li J, Cai H, Strom S, Bisello A, Kelley DE, FriedmanEinat M, Skibinski GA, Mccrory MA, Szalai AJ \& Zhao AZ. Induction of leptin resistance through direct interaction of C-reactive protein with leptin. Nature Medicine 200612 425-432.

54 Meier-Ewert HK, Ridker PM, Rifai N, Regan MM, Price NJ, Dinges DF \& Mullington JM. Effect of sleep loss on C-reactive protein, an inflammatory marker of cardiovascular risk. Journal of the American College of Cardiology 200443 678-683.

55 Nixon GM, Thompson JM, Han DY, Becroft DM, Clark PM, Robinson E, Waldie KE, Wild CJ, Black PN \& Mitchell EA. Short sleep duration in middle childhood: risk factors and consequences. Sleep 200831 71-78.

56 Yu Y, Lu BS, Wang B, Wang H, Yang J, Li Z, Wang L, Liu X, Tang G, Xing $\mathrm{H}, \mathrm{Xu} \mathrm{X}$, Zee PC \& Wang X. Short sleep duration and adiposity in Chinese adolescents. Sleep $2007301688-1697$.

Received 19 August 2008

Accepted 20 August 2008 